\title{
Influence of complex chemical additives on the water resistant silicate materials
}

\author{
Olena Hryhorenko ${ }^{1, *}$, Anastasia Lobanova ${ }^{1}$, Ibrahim Kazimagomedov ${ }^{1}$, \\ Kyrylo Plakhotnikov ${ }^{1}$, and Olexandr Lulyko ${ }^{1}$ \\ ${ }^{1}$ Kharkiv National University of Civil Engineering and Architecture, Building Materials and Products \\ Department, Sumska st. 40, 61002 Kharkiv, Ukraine
}

\begin{abstract}
In this paper, it has been established that the use of silica fume, low-base slag and calcium hydroxide to modify clays in constrained contact conditions leads to an increase in the number of contacts between the particle components and provides the conditions for the formation of strong contacts and the formation of dense microstructures, and therefore reduces its water absorption and increases water resistance of unburned building materials based on local aluminum silicate raw materials.
\end{abstract}

\section{Introduction}

The increasing water resistance of unburned building materials based on local aluminum silicate raw materials is very difficult and complex task which depends on many factors and can be solved using the methodology of system analysis. The main problem in production of building materials by unburned material technology from local clays is their complex and heterogeneous polymineral and granulometric composition. This problem can be efficiently solved by carrying out experimental studies with the construction of a model for substantiation of the solution.

\section{Theoretical part}

The loam soil with a plasticity number of 14.35 from the Kharkovskoye-2 brick raw material field was used for the study. Visually, the initial mixture consists of loose redbrown rock with the carbonate content to $3 \%$. The granulometric and chemical composition of the clay used is shown in Tables 1 and 2.

Table 1. Size distribution of the clay used in the study, \%

\begin{tabular}{|c|c|c|c|}
\hline \multicolumn{4}{|c|}{ Particle size, $\mathrm{mm}$} \\
\hline more than 0.1 & $0.1-0.05$ & $0.05-0.005$ & less than 0.005 \\
\hline 12.32 & 21.83 & 44.65 & 21.20 \\
\hline
\end{tabular}

\footnotetext{
* Corresponding author: elenkagrigorenko@meta.ua
} 
Table 2. Chemical composition of the clay used in the study

\begin{tabular}{|c|c|c|c|c|c|c|c|c|c|}
\hline \multicolumn{1}{|c|}{ Content of components, \% } \\
\hline $\mathrm{SiO}_{2}$ & $\mathrm{Al}_{2} \mathrm{O}_{3}$ & $\mathrm{Fe}_{2} \mathrm{O}_{3}$ & $\mathrm{TiO}_{2}$ & $\mathrm{MgO}$ & $\mathrm{CaO}$ & $\begin{array}{c}\mathrm{Na}_{2} \mathrm{O} / \\
\mathrm{K}_{2} \mathrm{O}\end{array}$ & $\mathrm{SO}_{3}$ & $\mathrm{H}_{2} \mathrm{O}^{+}$ & $\mathrm{H}_{2} \mathrm{O}^{-}$ \\
\hline 77.20 & 9.14 & 3.16 & 0.61 & 1.01 & 2.10 & 1.31 & 0.31 & 3.22 & 1.94 \\
\hline
\end{tabular}

Table 1 shows that the loam silt used has a high content of fraction $(44.65 \%)$. By the number of its plasticity the sample is classified as heavy loam. The significant number of loam particles of the size less than $0.005 \mathrm{~mm}(21.2 \%)$ in the clay determines the interaction between colloidal particles which means the consequence of molecular attraction and electrostatic forces directly between the particles themselves and between particles and water molecules contained in the loam. The presence of highly dispersed clay particles in the loam (more than $65 \%$, Table 1) contributes to the increase in strength of clay materials, especially when they are firmed.

The chemical composition (Tab. 2) shows a high content of silica fume in the rock that characterizes the studied loam as acidulous.

The mineralogical composition of the clay was investigated by X-ray analysis method. The mineralogical composition was studied by means of X-ray diffraction analysis using a DRON-1.5 diffractometer. The results are shown in Fig. 1.

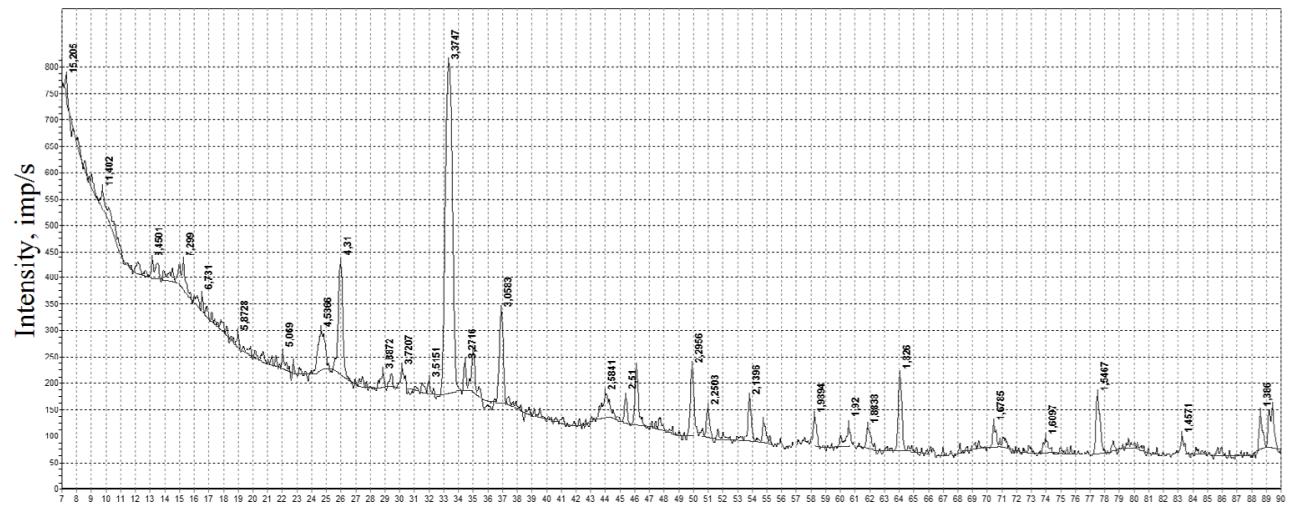

Fig. 1. X-ray diffraction pattern of the clay raw material before the modification.

The diffraction reflects the peaks characteristic for quartz stacking distances - 4.31, $3.37,2.47,2.29,2.14,1.83,1.55,1.39 \AA$ ), dickite $-\beta$-form $\mathrm{Al}_{2} \mathrm{O}_{3} \cdot 2 \mathrm{SiO}_{2} \cdot 2 \mathrm{H}_{2} \mathrm{O}$ (stacking distances - 7.299, 4.54, 3.72, 2.58, 2.51, 2.25, 1.68, $1.46 \AA$ ), halloysite (stacking distances $-11.37,5.87,4.51,3.51,1.68 \AA$ ) and calcite (stacking distances - 3.88, 306, 2.09, 1.92, 1, $88 \AA$ ).

There are also marks of micaceous minerals, feldspars and iron oxides in the material, which are accessory clay minerals. The presence of the background on the X-ray allows us to assume the presence of an X-ray amorphous phase in the sample.

Thermal-oxidative breakdown was studied by differential thermal (DTA) method of analysis on the derivatograph of F. Paulik and L. Erdei (Hungary) in the temperature range $20-1000^{\circ} \mathrm{C}$ at a heating rate of $10 \mathrm{deg} / \mathrm{min}$ in open atmosphere. The sample weighted 100 $\mathrm{mg}$. Three curves for the heating process of the samples were recorded during the study: Tcurve for the temperature change, TG-curve for sample weight change during heating and DTA curve for the change in enthalpy.

Thermographic studies showed typical effects in the DTA curve (Fig. 2) for the samples of the Kharkivskoye-2 loam field which is typical for various clay minerals. 


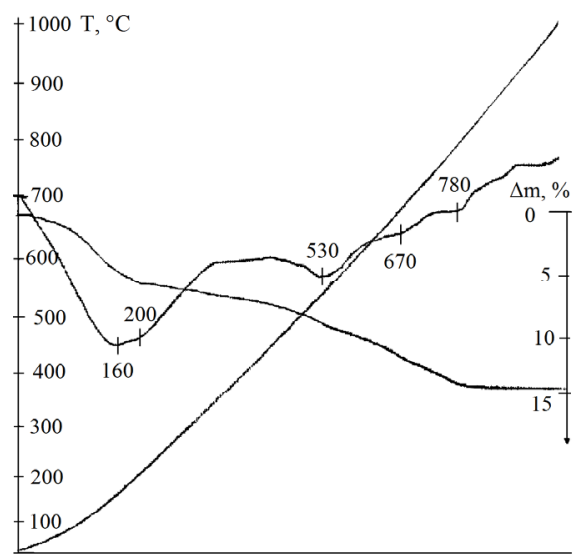

Fig. 2. Thermogram of loam samples in the study.

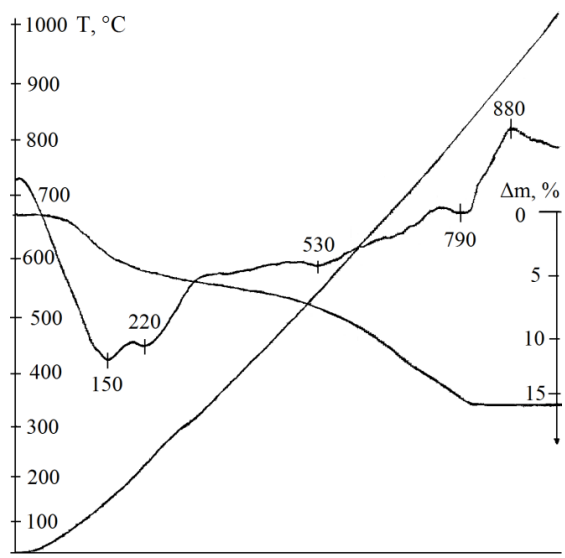

Fig. 3. Thermograms of the samples of the water-resistant clay-lime-slag material.

On DTA thermograms of loam samples (Fig. 2), the intense endothermic effect with a maximum at temperature of $160^{\circ} \mathrm{C}$ is caused by the removal of adsorbed water. The endoeffect in the area of $530^{\circ} \mathrm{C}$ may indicate the constitutional allocation of water with the destruction of the dickite crystal lattice. The third exothermic effect at $920^{\circ} \mathrm{C}$ is concerned apparently with the crystallization of the amorphous silica.

The quantitative mineralogical composition of brick raw materials at the Kharkovskoye2 field is shown in Tab. 3 .

Table 3. The mineralogical composition of the clay used

\begin{tabular}{|c|c|c|c|c|}
\hline \multicolumn{4}{|c|}{ Content of components, \% } \\
\hline quartz & dickite & halloysite & calcite & $\begin{array}{c}\text { mixed-formation and X-ray amorphous } \\
\text { phase }\end{array}$ \\
\hline 47 & 14 & 3 & 2 & 34 \\
\hline
\end{tabular}

The particle dispersion of the raw material investigated contributes to the increase in strength of clay raw materials, especially if they are intensively densified.

The thermodynamic instability and polymineral composition of the rock presented indicate the possibility of stabilizing the structure of the aluminosilicate raw material presented by interacting with modifying binder additives containing the exchange cations $\mathrm{Mg}^{2+}, \mathrm{Ca}^{2+}, \mathrm{Sr}^{2+}, \mathrm{Ba}^{2+}, \mathrm{Al}^{3+}, \mathrm{Fe}^{3+}$ in their composition, which interaction with hydroxyl OHclay minerals at elevated values of $\mathrm{pH}$ leads to exchange of a hydrogen by a cation of this metal with formation of more stable structures.

As a result of the studies [1-8], it has been established that the production of waterproof materials is based on unburned clays which can be obtained by addition of complex modifying additives with slag-alkali materials (silica fume, slags and hydrated lime) in their composition. Thus, a water-resistant composition with a compressive strength of $10.7 \mathrm{MPa}$, a flexural strength of $8.4 \mathrm{MPa}$, the softening coefficient $\mathrm{K}_{\mathrm{p}}=0.83$, the water absorption $\mathrm{Wm}=8$ and the freeze resistances $\mathrm{F}=50$ cycles was developed.

The formation of waterproof unburned building materials based on aluminosilicate raw materials depends on the formation of sparingly soluble hydrate compounds of clay minerals. In order to analyze the structure, phase and mineralogical composition of waterproof construction materials based on unburned clays obtained as a result of experimental studies, a number of studies were carried out with microscopy, X-ray and thermogravimetric methods of analysis. 
The aim of the study was to establish the restructuring of clay materials in the samples with the optimum composition of slag, silica fume and lime, after heat and moisture treatment, in a dry and moist state, and to compare the data obtained with ordinary clay (Fig. 1). The X-ray diffraction pattern of the water-resistant clay-lime-slag material studied is shown in Fig. 4.

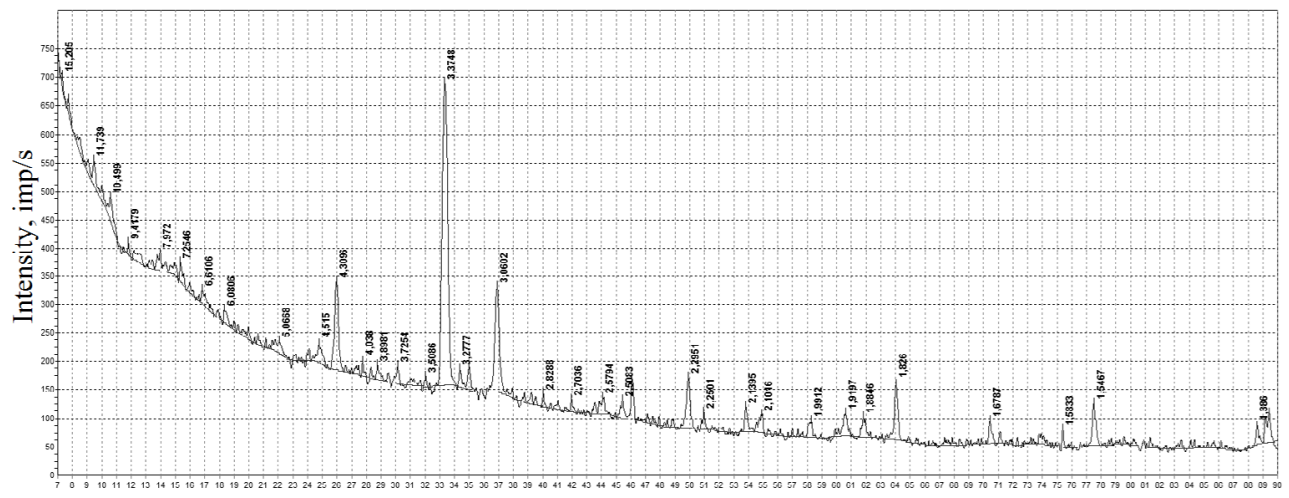

Fig. 4. X-ray phase analysis of the samples of studied water-resistant clay-lime-slag material.

The most intense lines in Fig. 4 refer to quartz contained in clay. Besides, the X-ray diffraction pattern in Fig. 4 contains lines of diffraction reflection of the same mineral phases as in the clay sample in Fig. 1. However, the X-ray diffraction pattern shows the presence of diffraction reflection lines of the following compounds:

- $2 \mathrm{CaO} \cdot \mathrm{Al}_{2} \mathrm{O}_{3} \cdot 8 \mathrm{H}_{2} \mathrm{O}$ - hexagonal eight-aqueous calcium hydroaluminate with the interplanar distances $\mathrm{d}=10,499 ; 2.83 ; 2.7 \AA$;

- $4 \mathrm{CaO} \cdot \mathrm{Al}_{2} \mathrm{O}_{3} \cdot 19 \mathrm{H}_{2} \mathrm{O}$ - four-calcareous nineteen-aqueous hydroaluminate with the interplanar distances $\mathrm{d}=10.6 ; 4.04 ; 2.83 ; 2.71 \AA$;

- $\mathrm{Ca}_{3} \mathrm{Si}_{6} \mathrm{O}_{15} \cdot 7 \mathrm{H}_{2} \mathrm{O}$ - hydrosilicate of nekoite-type with the interplanar distances $\mathrm{d}=9.42$; $7.97 ; 2.82 \AA$.

The thermogram of DTA samples of the clay-lime-slag composition investigated is shown in Fig. 3.

On the DTA thermograms of the test samples (Fig. 3), the intense endothermic effect with the maximum at a temperature of $150^{\circ} \mathrm{C}$ is caused by the removal of adsorbed water and the crystallization water of calcium hydroaluminates. The endo-effect at $530^{\circ} \mathrm{C}$ may indicate the dehydration of $\mathrm{Ca}(\mathrm{OH})_{2}$ and dickite. The third endothermic effect at a temperature of $790^{\circ} \mathrm{C}$ is obviously associated with the dissociation of calcite $\left(\mathrm{CaCO}_{3} \rightarrow \mathrm{CaO}+\mathrm{CO}_{2}\right)$. In Fig. 3 the thermogram displacement and subsidence of the endothermic peak associated with the dissociation of calcite $\left(780^{\circ} \mathrm{C}\right)$ into the region of higher temperatures (up to $790^{\circ} \mathrm{C}$ ) are observed. This subsidence, as well as the presence of a clearly expressed exoeffects in the area $880^{\circ} \mathrm{C}$, indicates the presence of nekoite-type neoformations in the hardened clay-lime-slag material, and is explained by its dehydration ((-) $\left.700-750^{\circ} \mathrm{C}\right)$ and further crystallization of dehydration products $\left((+) 750-800^{\circ} \mathrm{C}\right)$.

To analyze the structure of samples of waterproof building materials, microstructural studies were carried out using an optical microscope with a 600 -fold magnification. A microstructural analysis of modified samples after heat and moisture treatment was carried out, as standard samples of unmodified clay were taken (Fig. 5). 


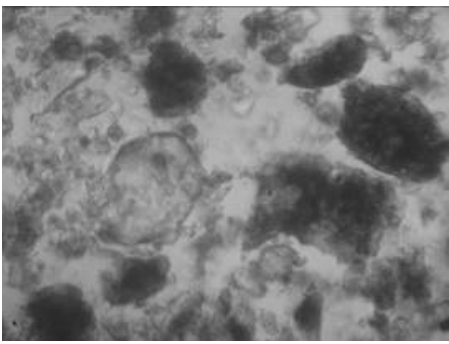

(a)

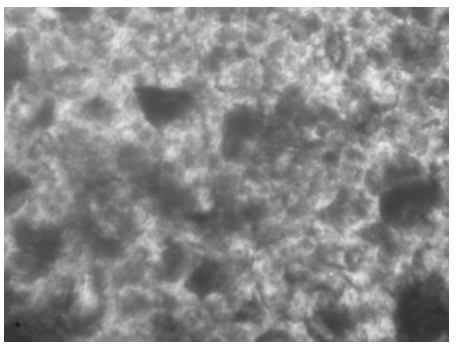

(b)

Fig. 5. Microstructure of clay samples: (a) unmodified clay; (b) modified clay.

In a sample of unmodified clay (Fig. 5a), a disordered lumpy micro texture is observed, being typical for alluvial clays.

Addition of a modifier and implementation of the process in constrained contact conditions (Fig. 5b) lead to formation of the coagulation-crystallization structure. The structure has a higher density than unmodified clay, although the preparation conditions in both cases are similar (pressing pressure $20 \mathrm{MPa}$ ). In the sample in Fig. $5 \mathrm{~b}$ formation of the structure of newgrowths is observed in the form of low-basic calcium hydrosilicates hypothetically. Crystalloptical studies were carried out using POLAM-L211 and MIN-8 microscopes with the use of immersion liquids (Fig. 6).

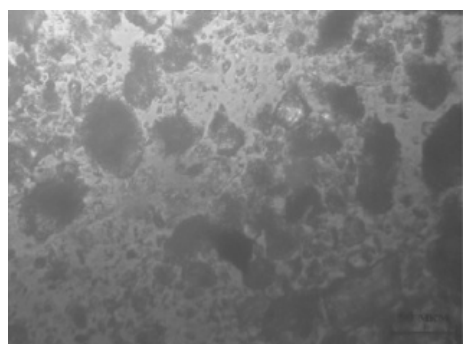

(a)

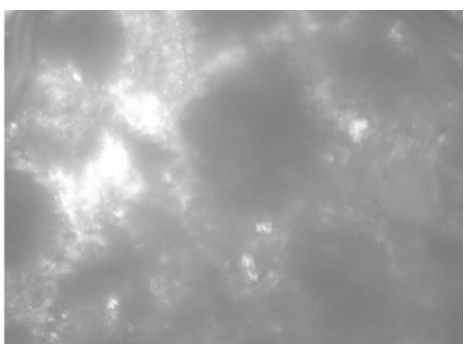

(b)

Fig. 6. Micrograph of the immersion specimen of a clay-lime-slag material sample: (a) in transmitted light without analyzer; (b) in polarized light with an analyser.

Microscopically, immersion preparations are represented by three phases (Fig. 6):

1) an amorphous isotropic bunched siliceous mass (clot size 20-50 $\mu \mathrm{m}$ ), the content of which is $\sim 60$ vol. \%;

2) fine crystalline quartz (grain size 3-7 $\mu \mathrm{m}$ ) 25 vol. \%;

3 ) the transparent grains of the carbonate phase are presented in the form of spherulites (from 10 to $25 \mu \mathrm{m}$ ), whose content is $\sim 15 \mathrm{vol} . \%$.

In Fig. 6b, the anisotropic crystalline phase is clearly visible in the form of separate luminous grains against the background of an isotropic amorphous basic siliceous mass.

The composition and structure of crystalline newgrowths and their phase composition were studied by IR spectroscopy (Fig. 7).

The spectrum shows bands of crystalline quartz: 460, 480, 700, 790, 810, 1080 and $1190 \mathrm{~cm}^{-1}$ clearly. Wide blurred bands in the region of 1460-1540 and 2900-2940 refer to the carbonate phase, probably represented by polymorphic modification of calcium carbonate. 


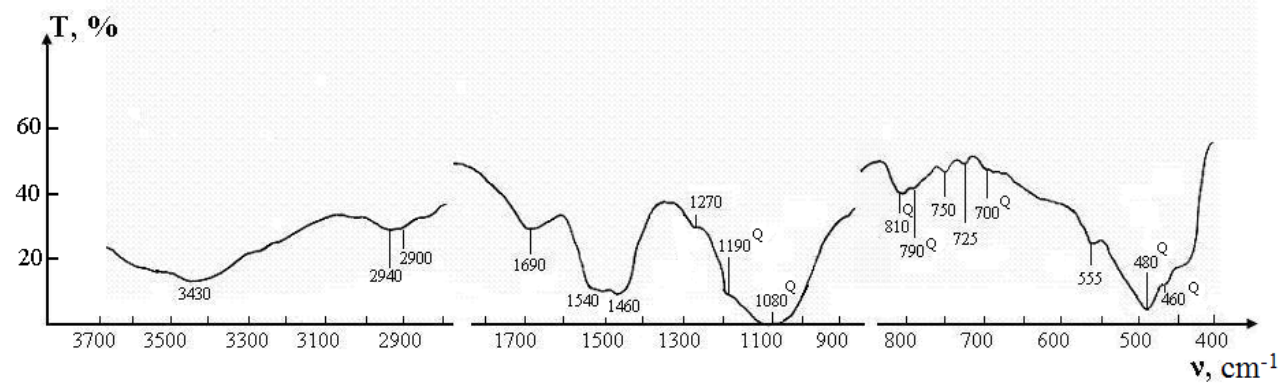

Fig. 7. Infrared absorption spectrum of a sample of clay-lime slag material: $\mathrm{Q}$ - bands of crystalline quartz $\left(\mathrm{SiO}_{2}\right)$.

The presence of a small but clearly defined peak of $555 \mathrm{~cm}^{-1}$, small bands of 725 and $750 \mathrm{~cm}^{-1}$, as well as the characteristic position and shape of the bands in the region of valence and deformation vibrations of molecular water $\left(\mathrm{H}_{2} \mathrm{O}\right)$ indicate large amount of hydrated amorphous silica. It is confirmed by the data of crystal-optical analysis.

The data obtained with the help of IR spectroscopy make it possible to conclude that this sample consists of three main phases:

1) fine crystalline quartz ( 25 vol. \%);

2) hydrated amorphous silica (60 vol.\%); and

3 ) calcium carbonate (presumably, vaterite) (15\% vol.\%).

The results of electron microscopic studies of the structure of the clay raw material used, the composition of the developed composition and the composition of the developed composition after water storage are shown in Fig. 8 to 10.

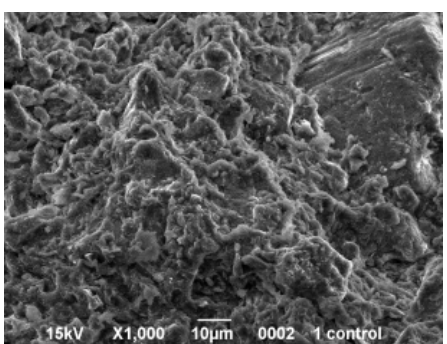

(a)

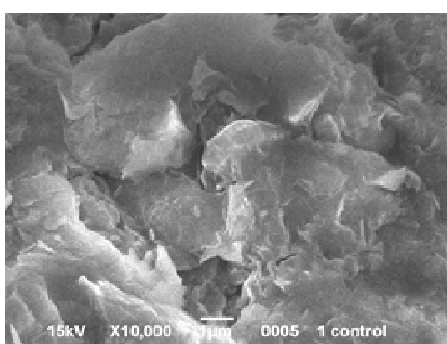

(b)

Fig. 8. The results of electron microscopic analysis of the clay raw materials structure used in the study: (a) $\times 1000$; (b) $\times 10000$.

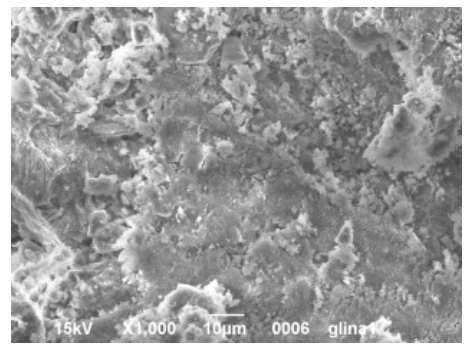

(a)

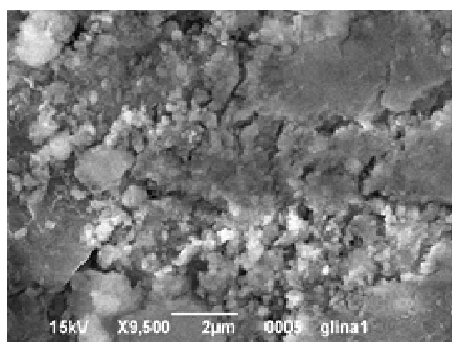

(b)

Fig. 9. The results of electron microscopic analysis of the structure of waterproof building materials based on the raw clay of the modified composition: (a) $\times 1000$; (b) $\times 9500$. 


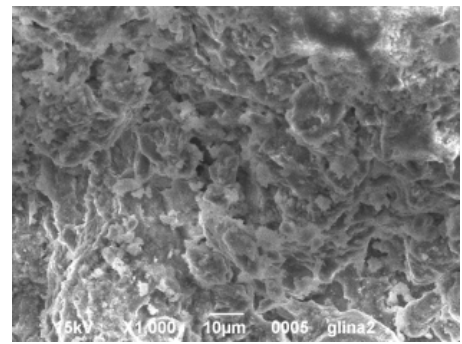

(a)

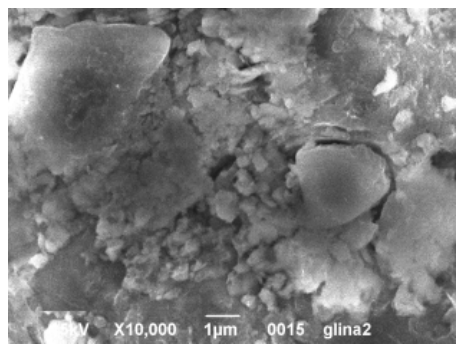

(b)

Fig. 10. The results of electron microscopic study of the structure of waterproof building materials based on the raw clay of the modified composition after storage: $(a) \times 1000 ;(b) \times 10000$.

Comparative characteristics of the samples show that the modification of the clay raw material with a calc-siliceous modifier in alkaline medium leads to the destruction of the crystalline structure of clay minerals (Fig. 8a) and to formation of an amorphous phase in the gel form (Fig. 9a), which fills the volume between particles of clay raw materials, leads to compaction of the modified material structure, and therefore reduces its water absorption and increases water resistance.

The microscopic and EMC research conducted allows us to refine the model of structure and structural elements of the unburned clay-lime-slag composition (Fig. 11).

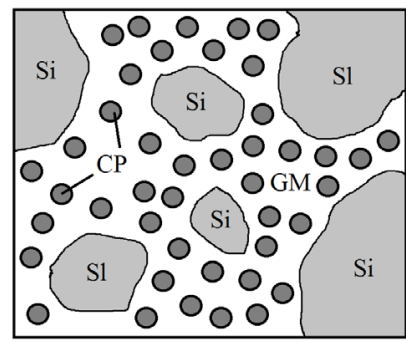

(a)

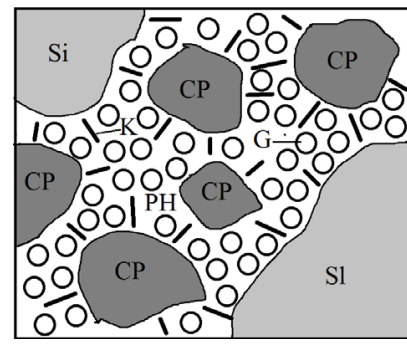

(b)

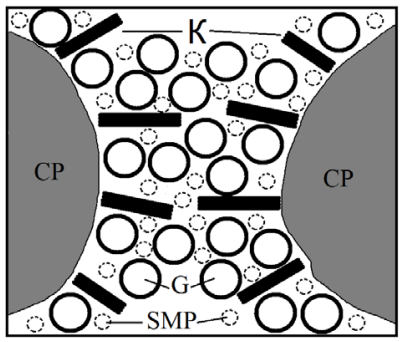

(c)

Fig. 11. Structure model of the unburned clay-slag composition elements on: (a) meso-, (b) micro-, (c) submicro-level; $\mathrm{Si}$ - quartz sand $(0,2$ - 1,25 mm); Sl - large grains of unreacted slag $(0,2$ $0,63 \mathrm{~mm}) ; \mathrm{GM}$ - a gelatinous mass; $\mathrm{CP}$ - not completely reacted clay particles $(50-100 \mu \mathrm{m}) ; \mathrm{K}-\mathrm{sub}$ microcrystalline splices of hydrated newgrowths $(0.5-10 \mu \mathrm{m}) ; \mathrm{G}$ - particles of hydro silicate gel; PH - the products of hydration of the slag-alkali component; SMP - sub micropores $(3-8 \mathrm{~nm})$.

The material used in this study is the multilevel matrix filled composite. At the macro level, the composition is homogeneous, since there is no large filler. The granulometric composition used for the study of clay (Table 1), and the dispersion additives used for the modification is no more than $1.25 \mathrm{~mm}$. Therefore, at the meso-level (Fig. 11a), the filler will be quartz sand contained in clay rock, and large grains of unreacted slag (mainly its crystalline phase), and the matrix is gel-like mass consisting of hydrated newgrowths. At the micro-level (Fig. 11b), the matrix is hydration products of the slag-alkali component, and the filler is fine-dispersed clay particles. At the sub micro-level (Fig. 11c), the matrix is hydrosilicate gel, and the filler is sub microcrystalline splices of hydrated newgrowths of diffuse structure and crystal sizes. At the sub micro-level, there is an increased content of sub micropores measuring $3 \pm 8 \mathrm{~nm}$ (Fig. 11c). 


\section{Conclusions}

This study shows that the use of silica fume, low-base slag and calcium hydroxide to modify clays in constrained contact conditions leads to increase in the number of contacts between the particle components and provides the conditions for the formation of strong contacts and dense microstructures due to the synthesis of newgrowths in the form of calcium hydroaluminates, calcium carbonate in the form of vaterite and significant amount of hydrated amorphous silica.

\section{References}

1. A. Wandolovskiy, O. Hryhorenko, Sc. bull. constr., 72, 228-223 (2013)

2. O. Hryhorenko, Sc. bull. constr., 75, 205-208 (2014)

3. A. Wandolovskiy, O. Hryhorenko, Sc. bull. constr., 78, 143-145 (2014)

4. A. Wandolovskiy, O. Hryhorenko, T. Kostyk, Bull. of the Odessa St. Ac.y of Constr. and Architect., 60, 36-40 (2015)

5. A. Wandolovskiy, O. Hryhorenko, Sc. bull. Ukr. St. Ac. of Railw. Transp., 152, 199204 (2015)

6. A. Wandolovskiy, O. Hryhorenko, O. Dedeneva, Sc. bull. Inform. proces. sys., 3(140), 199-202 (2016)

7. A. Wandolovsky, N. Younis Basheer, Yousef Riyed AL-hawari, IJESIT, 6, 1-8 (2017)

8. O. Hryhorenko, A. Lobanova, The lat. techn., equip. and manag. sys. in const., 29-33 (2016) 